\title{
Guide to recordings
}

This is the guide to recordings that have been used and referenced in this grammar.

There are two major sets of such recordings: those that I made between 2015 and 2018, and those made by Isabel O’Keeffe between 2006 and 2015. Moreover, there are several recordings made by Carolyn Coleman, three recordings made by Aung $\mathrm{Si}$, and one by Ruth Singer.

The recordings that are of the format IK1-YYMMDD_XXXN are made by myself in the course of my field work (Kapitonov 2016a). They are to be found archived in PARADISEC at https: //catalog. paradisec.org. au/collections/IK1. The YYMMDD field indicates the date when the recording has been made. The XXX field distinguishes different sessions within the day, typically with different speakers. Finally, the last digit ('N') distinguishes several parts within a single recording session (and if there was only one recording produced in a given session, it is trivially ' 1 '). There are 192 recordings from my field work, made with 24 speakers of Kunbarlang. The audio files range from several lexical items to some very long (over an hour) elicitation sessions. Elicitations make up the majority of this part of my corpus; there are 13 narratives and dialogues in this collection, which are listed in Table 1 below.

The recordings that are of the format YYYYMMDD IB NN (e.g. 20060901IB03) and YYYYMMDD IOv NN (e.g. 20150413IOv01) are made by Isabel O’Keeffe. Recordings made by Aung Si are 20150212AS01, 20150212AS02, and 20150206AS03. They are archived with the Endangered Languages Archive (ELAR), see O'Keeffe et al. (2017), or see http: //hdl. handle. net/2196/00-0000-0000-0002-EF13-E@view and http://hdl. handle. net/2196/00-0000-0000-000F-BF4E-0@view. There are over a hundred items in this collection, and they likewise include both grammatical elicitation and free narratives. The proportion is the opposite to my collection, i.e. narratives prevail. The recording made by Ruth Singer is RS1-140, and it is archived with ELAR at http://hdl . handle . net/2196/00-0000-0000-0013-7C8C-A@view.

Carolyn Coleman's recordings are archived with AIATSIS, see https://aiatsis . gov.au/sites/default/files/catalogue_resources/coleman_c02_finding-aid. pdf, and with ELAR, see http://hdl.handle.net/2196/00-0000-0000-000F-BF4E0 @view. When referenced here, they begin with c01 or C02. Isabel O'Keeffe's efforts in obtaining copies of these recordings are acknowledged with much gratitude.

All recordings are subject to the speakers' discretion. They may be temporarily unavailable to public access. 
Tab. 1: List of spontaneous discourse recordings

\begin{tabular}{lll}
\hline Item & Topic & Speaker \\
\hline IK1-150801_1PN4 & Traveling along the coast & Paul Naragoidj \\
IK1-160510_0001 & Shipwreck & †eorge Djidurinjmak \\
IK1-160513_0011 & Feeding Fluffy & Sandra Makurlngu \\
IK1-160525_0001 & Speaker's youth & Peter Waralak \\
IK1-160525_0011 & Speaker's youth & Peter Waralak \\
IK1-160624_0001 & Mission Centennial & Rita Djitmu and Linda Najinga \\
IK1-160624_0021 & Outstation camping & Rita Djitmu and Linda Najinga \\
IK1-160719_0001 & Mission Centennial & Sandra Makurlngu \\
IK1-160726_0011 & Making damper & Sandra Makurlngu \\
IK1-160726_0021 & Making damper & Sandra Makurlngu \\
IK1-170610_2SM1 & Spot-the-Difference & S. Makurlngu and George Manmurulk \\
IK1-170615_1SY1 & Feeding Fluffy & Solomon Yalbarr \\
IK1-170625_1PN1 & Arrival of J. Watson to Mardbalk & Paul Naragoidj \\
\hline
\end{tabular}

